\title{
Sarcoidosis: Correlation of HRCT Findings with Results of Pulmonary Function tests and Serum Angiotensin- Converting Enzyme Assay
}

\author{
YOSHIKO MIMORI \\ Department of Medicine, Kurume University School of Medicine, \\ Kurume 830-0011, Japan
}

\begin{abstract}
Summary: We examined correlations between findings on chest high resolution computed tomography (HRCT), pulmonary function and values of serum angiotensin converting enzyme (ACE) in 25 patients with sarcoidosis. The most frequent CT features were small nodular opacities. The small nodules, representing the confluence of epithelioid granulomas, are strongly correlated with peribronchovascular, perilobular, and centrilobular lesions, where there is an abundance of lymphatic plexus. This strongly suggests the importance of the lymph vessels in the pathogenesis of sarcoidosis. The pulmonary functions tests showed obstructive defects in 6 and mixed-type defects in 2 of the 25 patients. Furthermore, an elevation of $\dot{\mathrm{V}}_{50} \dot{\mathrm{V}}_{25}$ ratio suggesting small-airway disease was detected in many patients who showed normal values of $\mathrm{FEV}_{1.0} \%$ and $\% \mathrm{VC}$. This fact indicates that small-airway disease was manifested earlier in sarcoidosis patients. Statistically significant negative correlations were found between visual score and \%VC, \%FVC, $\mathrm{FEV}_{1.0} \%, \% \mathrm{TLC}$, and \%DLCO, but there was no significant correlation between visual score and serum ACE. ACE is derived from granuloma-forming epithelioid cells, and the activity of ACE decreased rapidly in mature granulomas. Epithelioid cells in the mature granulomas which can be recognized on HRCT scan have stopped or are about to stop the release of ACE. In this study, serum ACE activity was found to be elevated and correlated with $\% \dot{\mathrm{V}}_{25}$ and $\dot{\mathrm{V}}_{50} \dot{\mathrm{V}}_{25}$ at an early stage of the disease. The results of this study provide meaningful insights into the process of sarcoidosis in lung.
\end{abstract}

Key words pulmonary sarcoidosis, HRCT, pulmonary function test, small-airway disease, serum angiotensin-converting enzyme

\section{INTRODUCTION}

Sarcoidosis is a multisystemic disorder of unknown cause characterized by the presence of noncaseating granulomas [1-3,5-7,10,11]. It may involve almost any organs $[1,6]$, but most morbidity and mortality is the result of pulmonary disease $[3,6]$. Pulmonary manifestations are present in $90 \%$ of patients $[6,15]$.

The purpose of this study was to elucidate the processes of the disease in the lung. We examined correlations between findings on chest high resolution computed tomography (HRCT), pulmonary function tests, and values of serum angiotensin converting enzyme (ACE).

\section{MATERIALS AND METHODS}

Subjects

The subjects were 25 patients with sarcoidosis (10 males and 15 females, mean age 45 years, ranging from 20 to 70 . Eleven were current or former smokers, 14 were nonsmokers) who had pulmonary abnormalities on high resolution CT with negative bacterial and fungal study. A histological diagnosis was made by transbronchial lung biopsy (TBLB) in 19 patients and by inguinal lymph node biopsy in 1 patient. In the remainder 5 patients, the diagnosis was made on the basis of analysis of bronchovascular 
lavage fluid (BALF) and findings on radiograms including Ga scan.

\section{Methods}

In all the patients, pulmonary function tests and measurements of serum ACE activity were performed within two weeks (mean: 5 days) of HRCT scanning. In 22 of the patients, analysis of arterial blood gas was carried out within a month of scanning. Pulmonary function was evaluated spirometrically and the following parameters were calculated: vital capacity as percent of the predicted value $(\% \mathrm{VC})$, forced vital capacity as percent of the predicted value $(\% \mathrm{FVC})$, forced expiratory volume in 1 second with the use of Gaensler $\left(\mathrm{FEV}_{1.0} \%\right.$ $\left.=\left[\mathrm{FEV}_{1.0} / \mathrm{FVC}\right] \times 100\right)$, flow curve at 25 percent VC as percent of the predicted value $\left(\% \dot{\mathrm{V}}_{25}\right)$, and the ratio of the flow curve at 50 percent $\mathrm{VC}$ to the flow curve at 25 percent $\left.\mathrm{VC}\left(\dot{\mathrm{V}}_{50}\right) \dot{\mathrm{V}}_{25}\right)$ using maximum spirometry flow-volume curve. In 15 patients, total lung capacity as percent of the predicted value (\%TLC) was estimated by a closed-circuit gas dilution method (helium method) and diffusing capacity as percent of the predicted value (\%DLco) by the single-breath method.

High resolution CT scanning was performed in the supine position during breath holding. The lung was scanned from the lung apex to $1 \mathrm{~cm}$ below the dome of the diaphragm using $10 \mathrm{~mm}$ collimation at intervals of $3 \mathrm{~mm}$ when the Pro seed scanner (Yokogawa Co., Japan) was used and $2 \mathrm{~mm}$ when the CT/T 9200 scanner (GE, USA) was used. All images were obtained at window levels appropriate for pulmonary parenchyma (mean, -700 to -900 HU; width, 1000-2000 HU) and mediastinum (mean, 30-50 HU; width, 400-500 HU).

Each individual section on the CT scan was assessed for the presence, pattern, and distribution of parenchymal and interstitial disease, and the findings were classified into the following 11 patterns.

1) nodule; nodules were defined as round, highattenuation, areas of less than $20 \mathrm{~mm}$ in diameter. The term micro-nodule was used for nodules of less than $3 \mathrm{~mm}$ in diameter (Fig. 1).

2) consolidation; consolidation was defined as a high attenuation area of more than $20 \mathrm{~mm}$ in diameter with or without cavity (Fig. 2a,b).

3) ground-glass opacity; ground-glass opacity was defined as areas of increased attenuation without obstruction of the underlying vessels and bronchi (Fig. 3).

4) septal line; septal line was defined as a regular or irregular thickening of interlobular septa (Fig. 4).

5) non septal line; non septal lines were linear areas of high attenuation distinct from interlobular septa or bronchovascular bundles.

6) subpleural curve linear opacity; linear opacities parallel to the subpleural curve representing partial atelectasis (Fig. 5).

7) small cyst area; small cyst areas were localized areas of decreased attenuation with well defined walls (Fig. 6).

8) architectural distortion; displacement of fissures, bronchi, and vessels (Fig. 7).

9) irregularly thickened bronchovascular bundles; (Fig. 8)

10) wall abnormality; wall abnormalities consisting of thickening of bronchial walls.

11) luminal abnormality; luminal abnormalities consisting of smooth or irregular and nodular occlusion or narrowing .

Each lung field was divided into 3 areas defined as follows: the upper zone above the level of the carina; the middle zone, between the level of the carina and the level of the inferior pulmonary veins;

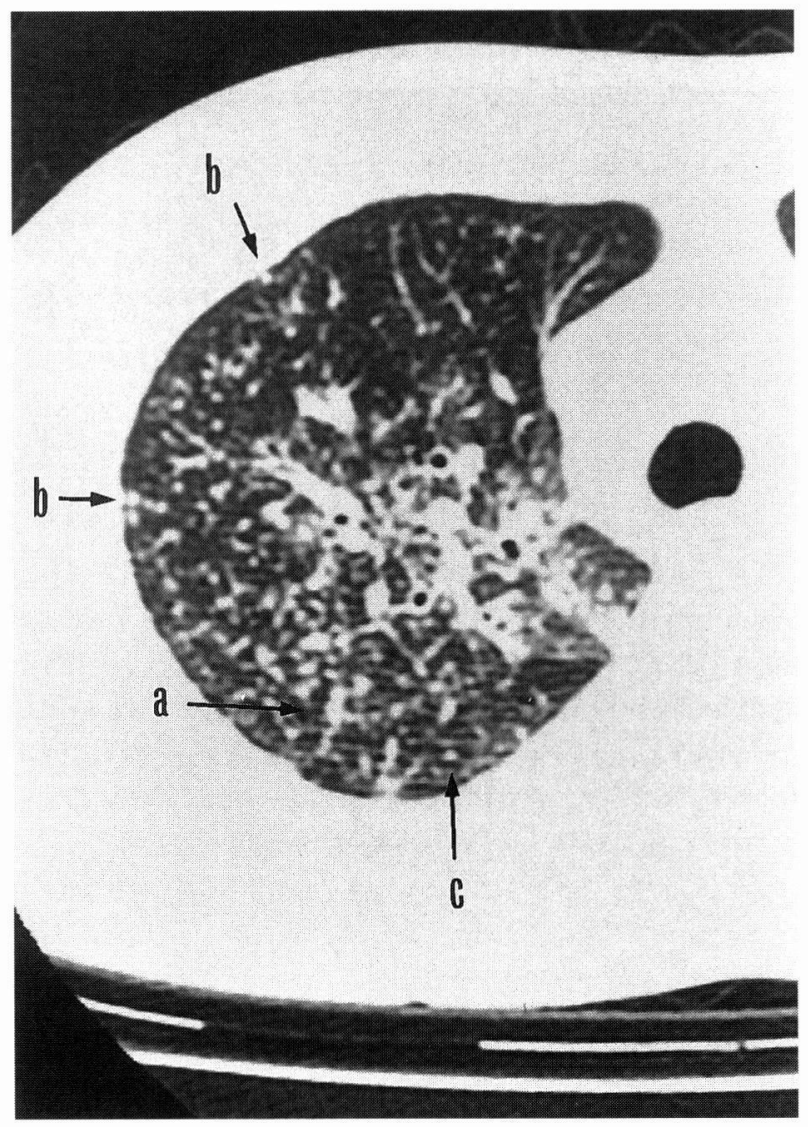

Fig. 1. Small nodule.

Appearance of small nodules with perilymphatic distribution. Peribronchovascular distribution (a), perilobular distribution (b), centrilobular distribution (c). 


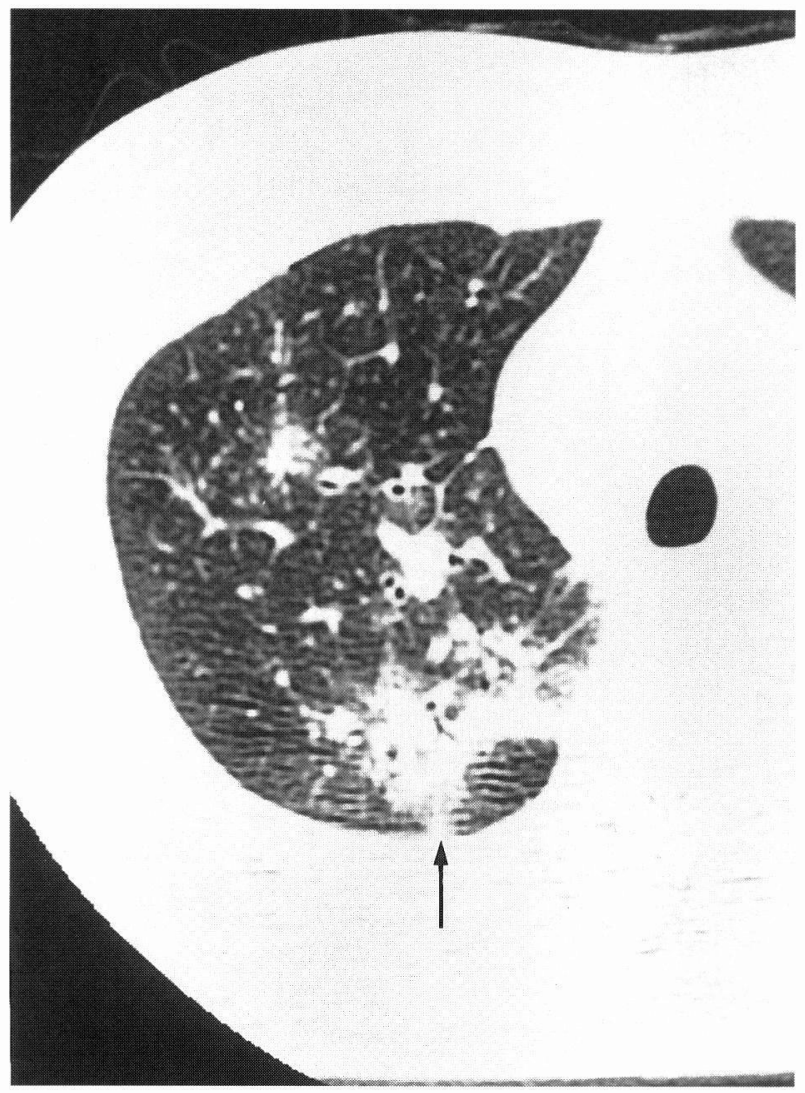

Fig. 2a. Consolidation (arrow).

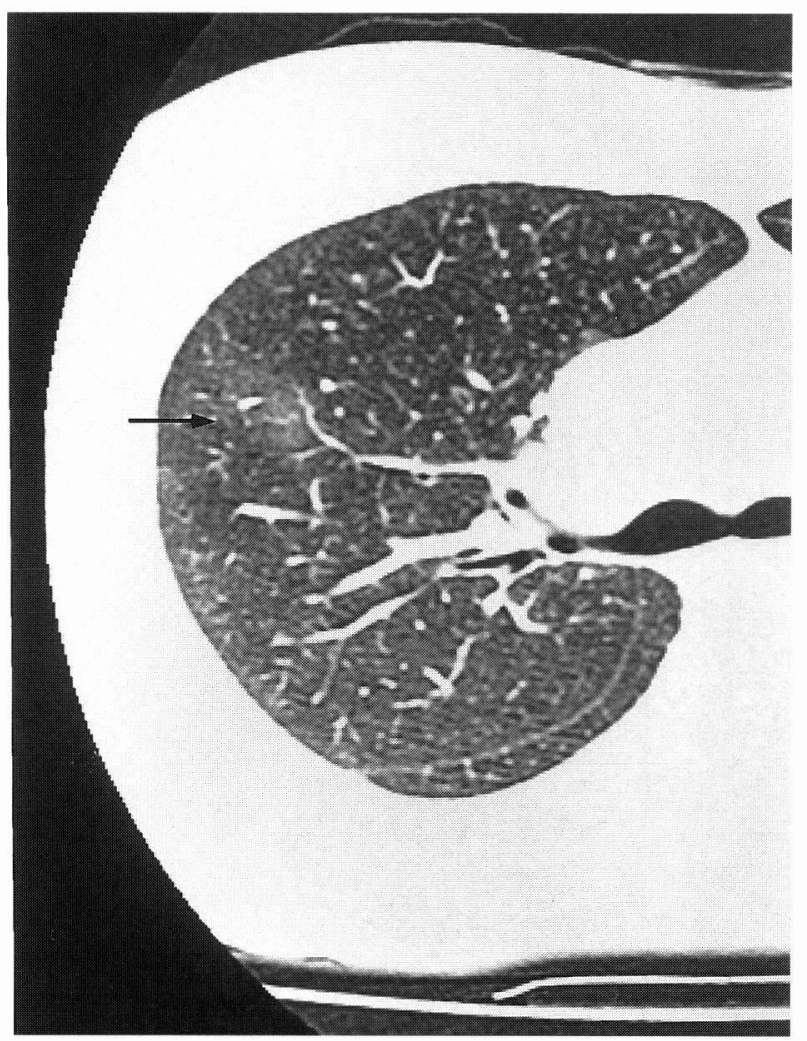

Fig. 3. Ground-glass opacity.

Ground-glass opacity is defined as a hazy increase in lung attenuation (arrow).

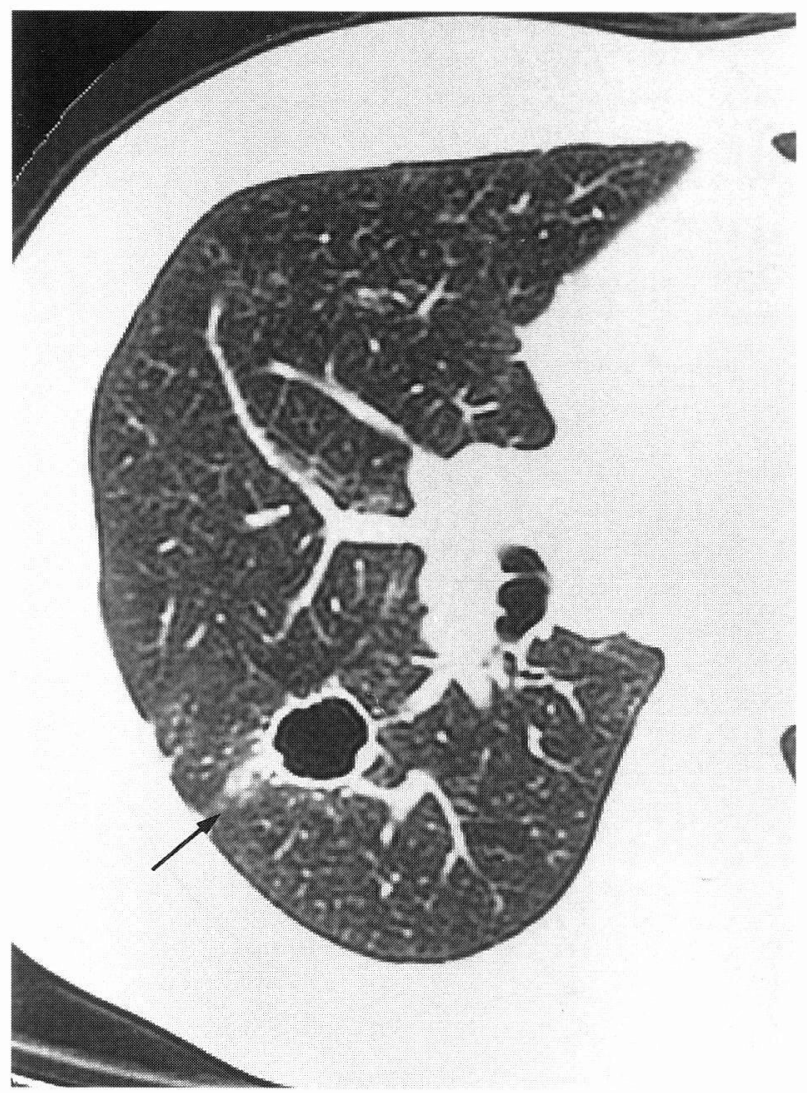

Fig. 2b. Consolidation with cavity (arrow).

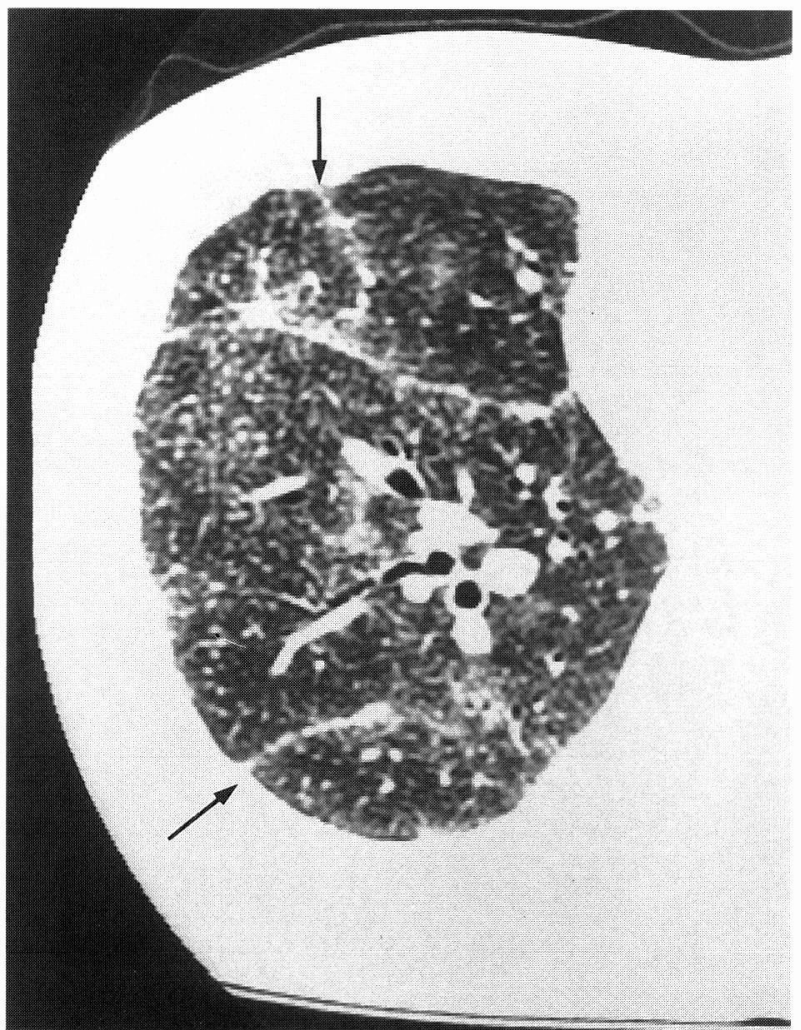

Fig. 4. Septal line.

Interlobular septal thickening resulting from sarcoido lesions (arrows). 


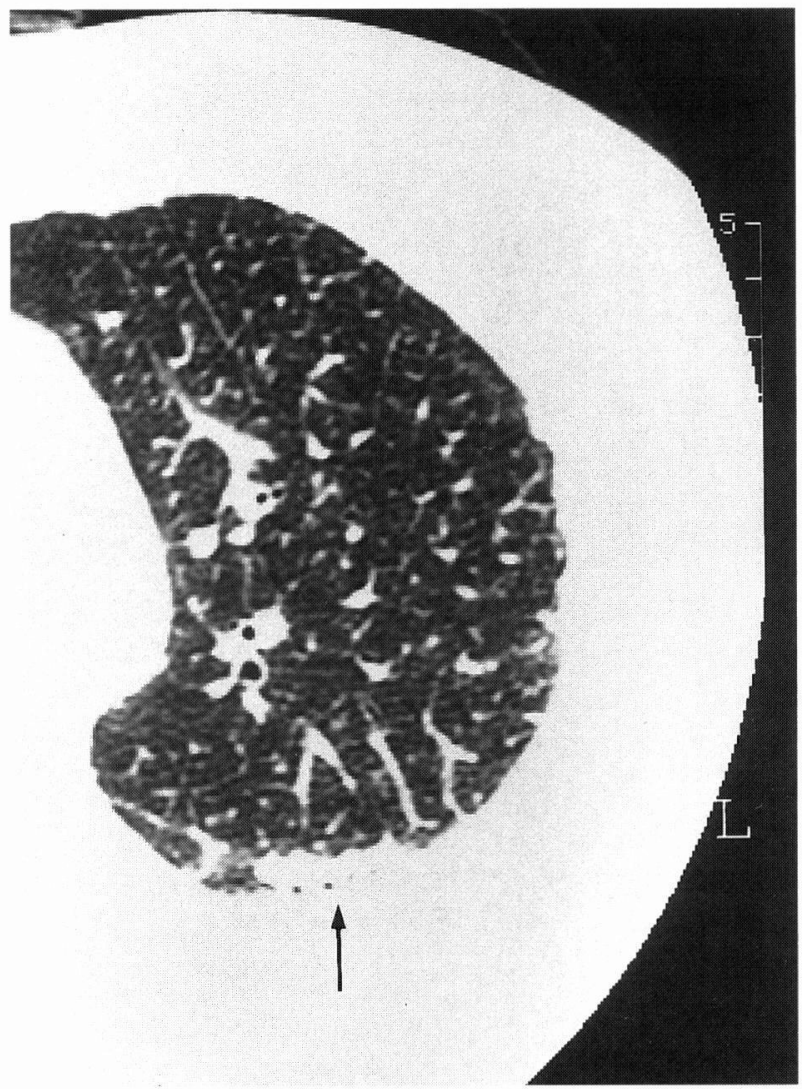

Fig. 5. Subpleural curve linear shadow.

A linear opacity parallel to the subpleural curve is visible (arrow).

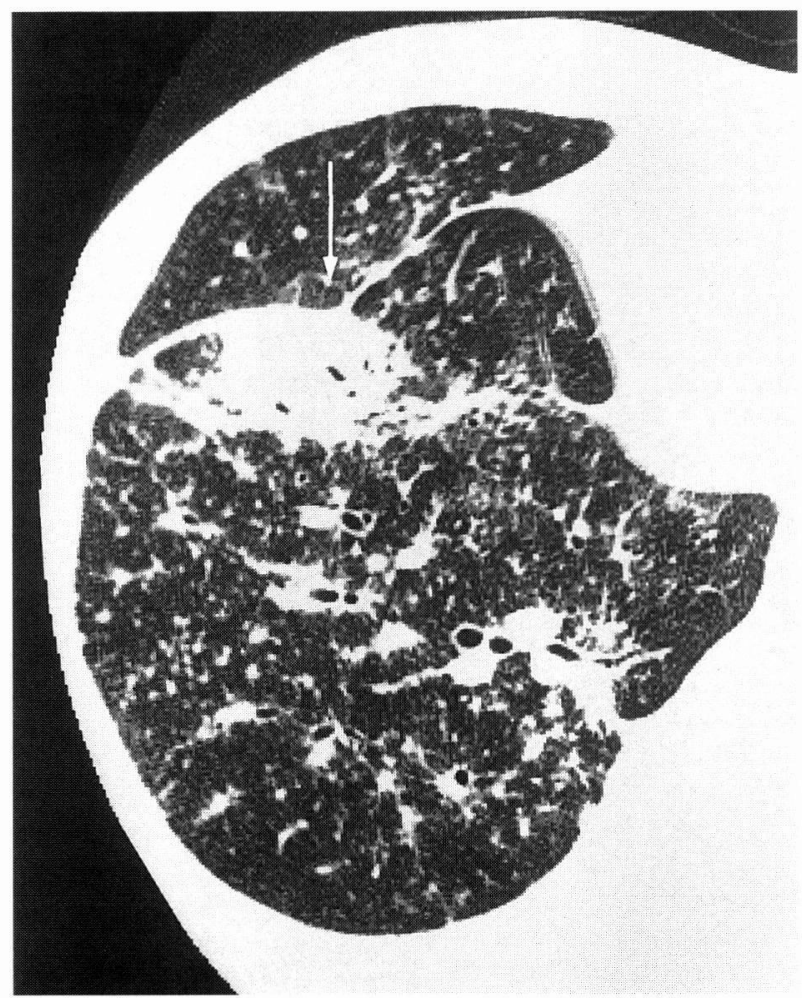

Fig. 7. Distortion.

The displacement of the fissure is due to the compression by the lesion adjacent to the fissure (arrow).

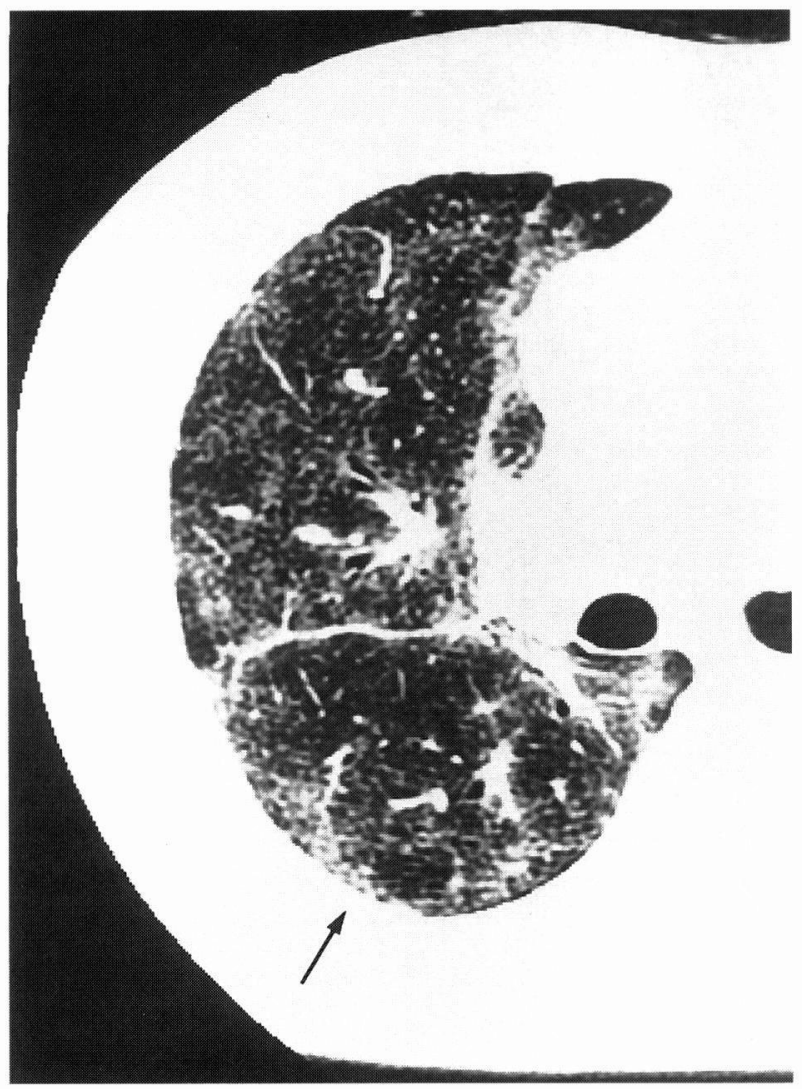

Fig. 6. Small cyst area.

A localized area of decreased attenuation with well defined walls in subpleural lesion (arrow).

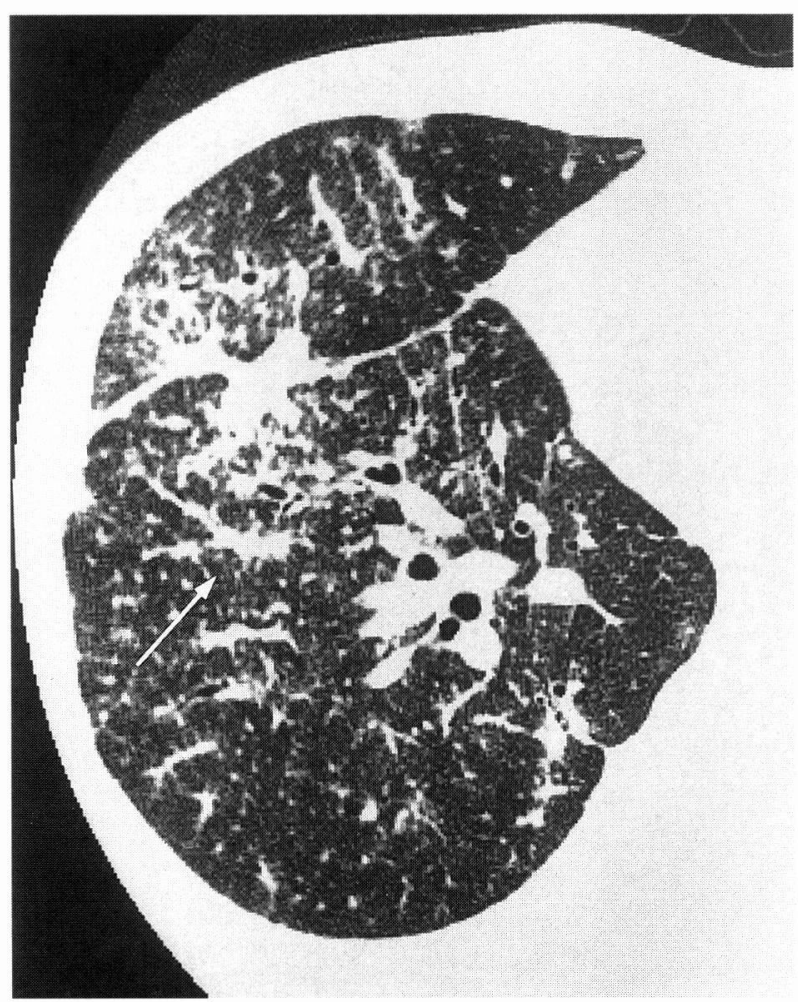

Fig. 8. Irregular bronchovascular bundle.

The thickening of bronchovascular bundles is visible (arrow). 


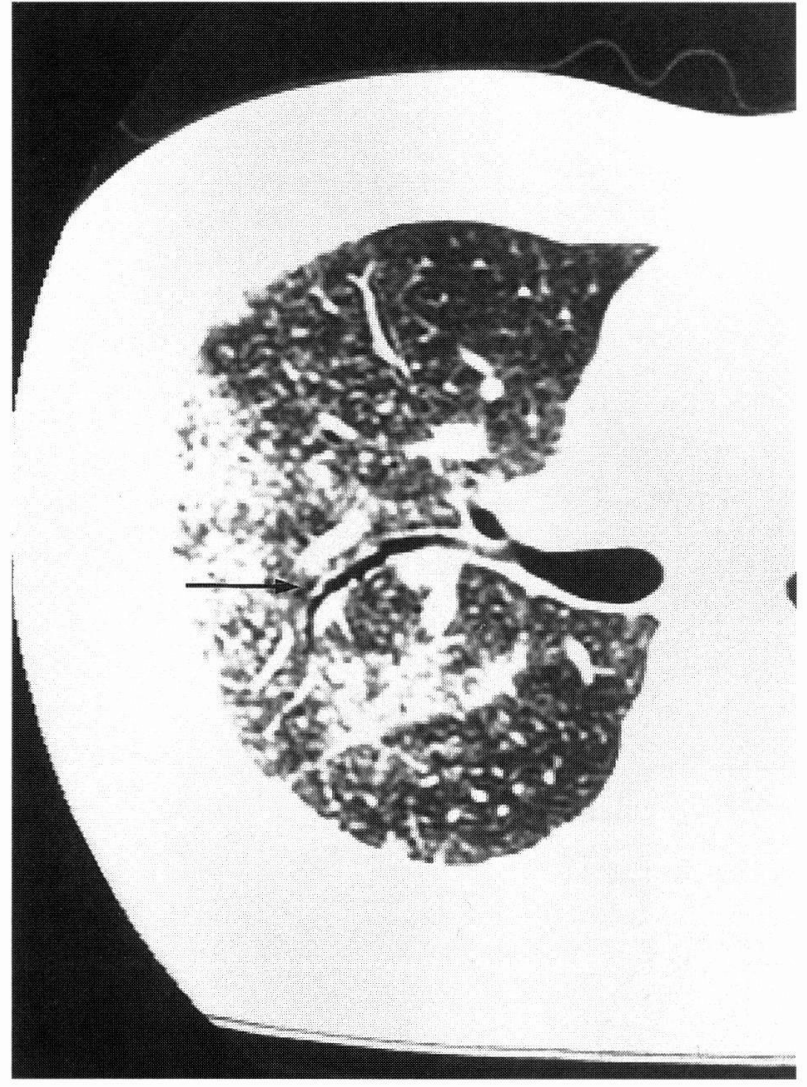

Fig. 9. Wall abnormality.

Thickening of the bronchial wall is visible (arrow).

and the lower zone, below the level of the inferior pulmonary veins. The presence of the opacities, classified into categories 1 to 8 as above, was recorded separately in the three areas of the lung to yield a total visual score of parenchymal opacities. The score was based on the percentage of lung parenchyma that showed evidence of each recorded abnormality, estimated as follows: 1 , involvement of less than $25 \%$ of the image; $2,25-50 \%$; $3,50-75 \%$; 4 , more than $75 \%$. The scores for each zone were then added to obtain a global extent score, ranging from 0 to 12 , referred to as the CT extent score of each CT abnormality. A total score of lung involvement was obtained by summation of the global extent score of all CT abnormalities, ranging from 0 to 96 , which is further referred to as the overall $\mathrm{CT}$ extent score of disease severity. Correlation between total visual score and variables of pulmonary function, serum ACE values and $\mathrm{PaO}_{2}$ were examined by Spearman test.

\section{RESULTS}

\section{HRCT}

The most frequently encountered abnormalities

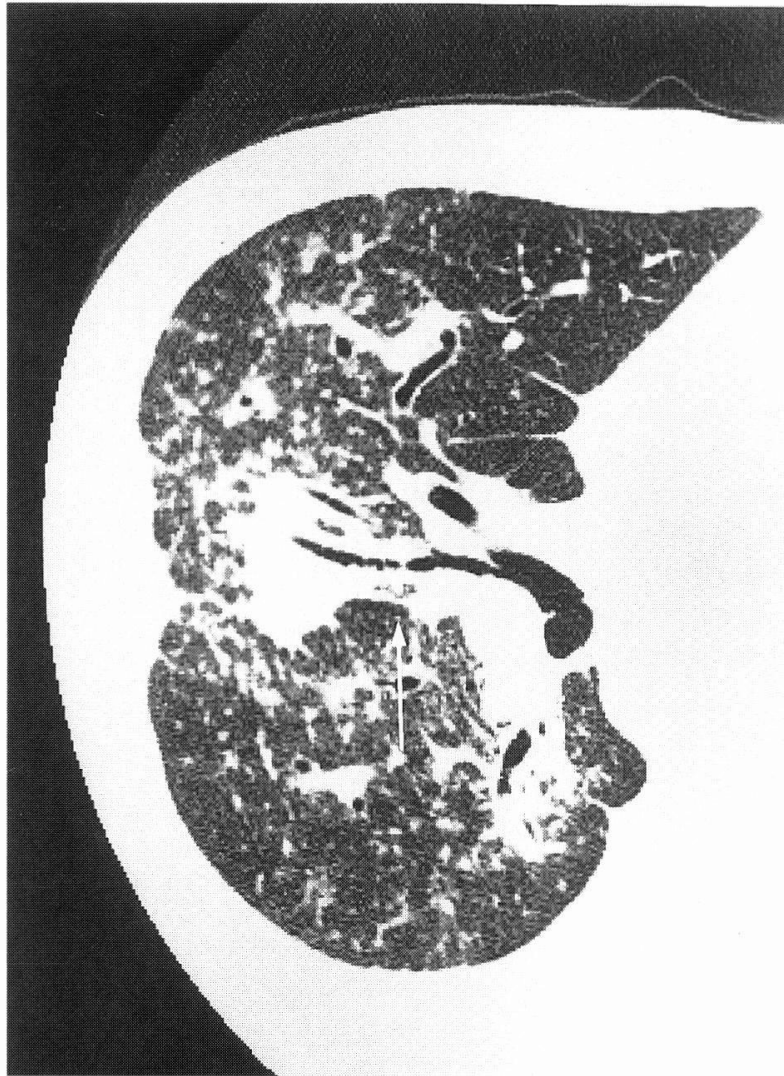

Fig. 10. Luminal abnormality.

The bronchial lumina are irregularly narrowed (arrow).

on HRCT were nodular opacities. In particular, micro-nodules less than $3 \mathrm{~mm}$ diameter were detected in all patients, followed by hilar or mediastinal lymph node swelling. These nodules were located in the peribronchovascular interstitium, in perilobular lesions (interlobular septa and subpleural lesion), and in centrilobular lesions (Fig. 1).

Consolidation, which is a confluence of small nodules $20 \mathrm{~mm}$ or more in diameter, with an irregular margin, was encountered in $8(32 \%)$ of the 25 patients, and was accompanied by cavity formation in 2 of them (Fig. 2a,b).

Thickened interlobular septa due to sarcoid granulomas along the lymphatics or small vessels in the interlobular septa, or fibrosis, were observed in 7 patients (28\%) (Fig. 3). Ground-glass opacity, referring to the presence on HRCT of a hazy increase in lung, was detected in more than half of the patients (64\%) (Fig. 4).

In contrast, non-septal lines, which are known to represent fibrotic changes in the pulmonary interstitium, were observed in only $4(16 \%)$ patients. Small cystic areas, which correspond to a micro honeycomb, were seen in even fewer patients $(2.8 \%)$ (Figs 5 and 6). Architectural distortion, the displace- 
TABLE 1.

$H R C T$ findings $(n=25)$

$\begin{array}{lrl}\text { nodule }(<20 \mathrm{~mm}) & 25 & (100 \%) \\ \text { consolidation }(\geqq 20 \mathrm{~mm}) & 8 & (32 \%) \\ \text { septal line } & 7 & (28 \%) \\ \text { non septal line } & 4 & (16 \%) \\ \text { SPCL } & 2 & (8 \%) \\ \text { ground-glass opacity } & 16 & (64 \%) \\ \text { distortion } & 7 & (28 \%) \\ \text { small cyst area } & 2 & (8 \%) \\ \text { irregular bronchovascular bundle } & 4 & (16 \%) \\ \text { wall abnormality } & 13 & (52 \%) \\ \text { luminal abnormality } & 3 & (12 \%) \\ \text { lymphadenopathy } & 24 & (96 \%) \\ \text { mediastinal lymph node } & 22 & (88 \%) \\ \text { hilar lymph node } & 19 & (76 \%)\end{array}$

TABLE 2.

Thin-Section CT extent score

\begin{tabular}{ll}
\hline \multicolumn{1}{c}{ Findings } & Mean \pm SD \\
\hline Nodule & $4.44 \pm 1.96$ \\
Consolidation & $0.60 \pm 1.00$ \\
Septal line & $0.48 \pm 0.87$ \\
Non septal line & $0.28 \pm 0.74$ \\
Distortion & $0.36 \pm 0.64$ \\
Ground-glass opacity & $1.80 \pm 1.96$ \\
Small cyst area & $0.80 \pm 0.28$ \\
\hline Total score & $8.00 \pm 5.12$ \\
\hline
\end{tabular}

ment of fissures, bronchi, and vessels, was revealed to be mainly due to the compression by swollen hilar lymph nodes or lesions adjacent to fissures.

Abnormalities of bronchi, an irregular thickening of the wall, or narrowing of lumen, were observed in 13 patients $(52 \%)$ but the grade of the abnormalities was mild, and an apparent swelling of the bronchovascular bundle was seen in only 4 patient $(16 \%)$. (Figs 8,9,10) Mean visual scores calculated based on the extent of individual findings in the six zones on thin sectioned CT scans are listed in Table 2. The mean total score was $8.00 \pm 5.12$.

\section{Pulmonary function tests}

The mean values of $\% \mathrm{VC}, \% \mathrm{FVC}, \mathrm{FEV}_{1.0} \%$, $\%$ TLC, \%DLco were within normal limits but the value of $\dot{\mathrm{V}}_{50} / \dot{\mathrm{V}}_{25}$ exceeded 3.0 , and obstructive defects were detected in $6(24 \%)$ patients and mixedtype in $2(8 \%)$. This study found that the nature of
TABLE 3.

Functional parameters and the value of serum $\mathrm{ACE}, \mathrm{PaO}_{2}$

\begin{tabular}{|c|c|c|}
\hline Functional Parameters & $\mathrm{n}$ & Mean $\pm \mathrm{SD}$ \\
\hline $\mathrm{VC}(\%)$ & $25(14)$ & $106.3 \pm 17.0(109.3 \pm 16.3)$ \\
\hline $\mathrm{FVC}(\%)$ & $25(14)$ & $105.9 \pm 17.2(108.4 \pm 16.6)$ \\
\hline $\mathrm{FEV}_{1.0}(\%)$ & $25(14)$ & $84.2 \pm 12.0(84.7 \pm 10.3)$ \\
\hline$\dot{\mathrm{V}}_{.25}(\%)$ & $25(14)$ & $46.6 \pm 20.3(41.3 \pm 11.1)$ \\
\hline$\dot{\mathrm{V}}_{50} / \dot{\mathrm{V}}_{25}$ & $25(14)$ & $3.3 \pm 1.1(3.9 \pm 1.1)$ \\
\hline $\operatorname{TLC}(\%)$ & $15(10)$ & $98.5 \pm 12.5(101.7 \pm 12.0)$ \\
\hline $\operatorname{DLCO}(\%)$ & $15(10)$ & $109.6 \pm 28.2(113.8 \pm 32.8)$ \\
\hline $\mathrm{PaO}_{2}(\mathrm{mmHg})$ & $22(12)$ & $85.1 \pm 11.9(82.0 \pm 13.1)$ \\
\hline SACE $(\mathrm{U} / \mathrm{mL})$ & $25(14)$ & $24.1 \pm 9.5(23.1 \pm 7.0)$ \\
\hline
\end{tabular}

*(Non Smoker)

TABLE 4.

Correlation between functional variables and $C T$ extent score

\begin{tabular}{ccc}
\hline Functional variables and SACE & $\gamma$ & $\mathrm{p}$ \\
\hline $\mathrm{VC}(\%)$ & -0.675 & $<0.001$ \\
$\mathrm{FVC}(\%)$ & -0.635 & $<0.002$ \\
FEV $_{1.0}(\%)$ & -0.635 & $<0.002$ \\
$\mathrm{TLC}_{(\%)}$ & -0.681 & $<0.02$ \\
$\mathrm{DLCO}(\%)$ & -0.555 & $<0.05$ \\
$\mathrm{PaO}_{2}$ & $\mathrm{NS}$ & $\mathrm{NS}$ \\
$\mathrm{SACE}$ & $\mathrm{NS}$ & $\mathrm{NS}$ \\
\hline
\end{tabular}

the ventilatory impairment in these patients was obstructive but not restrictive. An apparent defect in diffusing capacity was observed in only one patient.

To exclude the effect of smoking on the pulmonary function, we examined exclusively the values estimated in 14 non-smokers. In this group, obstructive defects were detected in 2 patients and mixed type defects in one among the 14 patients. In addition, in $9(81.1 \%)$ of 11 patients, who showed normal values of $\mathrm{FEV}_{1.0} \%$ and $\% \mathrm{VC}$, an elevated $\dot{\mathrm{V}}_{50} / \dot{\mathrm{V}}_{25}$ ratio with mean value of 3.9 was recognized. This fact indicates that abnormal small airway function is manifested earlier in sarcoidosis patients, preceding the reductions in $\% \mathrm{VC}$ and $\mathrm{FEV}_{1.0} / \mathrm{FVC}$.

Correlations between visual HRCT score and variables of pulmonary function test

Correlations between CT extent score and functional parameters are summarized in Table 4. Statistically significant negative correlations were found between visual score and $\% \mathrm{VC}, \% \mathrm{FVC}$, $\mathrm{FEV}_{1.0} \%, \% \mathrm{TLC}$, and \%DLco, but there were no significant correlations between visual score and 
serum ACE activity or $\mathrm{PaO}_{2}$. In non-smokers, however, negative low correlations were found between visual score and $\mathrm{PaO}_{2}(\mathrm{p}<0.05, \gamma=-0.662)$. Furthermore, in non-smokers, the value of $\mathrm{FEV}_{1.0} \%$ and serum ACE activity showed negative correlation $(p<0.02, \gamma=-0.67)$, and in the same group of patients, excluding the patients who showed abnormally low values of $\mathrm{FEV}_{1.0} \%$ and $\% \mathrm{VC}$, the serum ACE activity correlated negatively with $\% \dot{\mathrm{V}}_{25}$ $(\mathrm{p}=0.01, \gamma=-0.80)$ and positively with $\dot{\mathrm{V}}_{50} / \dot{\mathrm{V}}_{25}(\mathrm{p}<$ $0.01, \gamma=0.836$ ).

Thus, an association of serum ACE activity with airway disease, especially small airway disease, in sarcoidosis patients, is suggested by these data.

\section{DISCUSSION}

Sarcoidosis is a generalized granulomatous disease of unknown etiology. A majority (about 90\%) of the patients with this disease manifest pulmonary lesions including intrathoracic lymph node involvement [15]. Therefore, the lung is considered to be the most important organ in which to elucidate the disease processes, and many studies have focused on the investigation of pulmonary lesions. Radiographically, an attempt to elucidate the pathogenesis and disease processes has been made by examining the nature of the lesions and their distribution patterns in the lung $[1-8,20]$.

Diverse manifestations are demonstrated on HRCT scans of patients with sarcoidosis; the most characteristic abnormality consists of small nodules [15]. Small nodules of less than $3 \mathrm{~mm}$ in diameter representing the confluence of epithelioid granulomas, are most common, and they were detected in all patients in this study. The favorable sites in the lung parenchyma of granuloma formation are known to be the interstitium of the peripheral lung (subpleural tissue, interlobular septa containing veins and lymphatic branches, the connective tissue of centrilobular branches, the bronchioles and arterioles) and approximately $75 \%$ of the granulomas are found at these sites $[13,14]$.

Accordingly, the most frequently observed HRCT findings in the lung are nodular and/or ground-glass opacities and consolidations consisting of confluences of nodules, followed by irregularly thickened bronchial walls, swollen bronchovascular bundles and vessels [1-8,15,20]. Cavity formation has been reported in 3 to $5 \%$ of consolidative lesions $[15,17]$. In this study, cavities were detected in $2(8 \%)$ of 25 patients. Cavities representing bulla or bronchiectasis are common in patients with extensive fibrosis, however, in rare cases the pathogenesis may be ischemic necrosis of conglomerate granulomas. Ground-glass opacities are reported to represent area of active alveolitis. In this regard, Nishimura et al. [20] reported on a histopathological examination of biopsied or necropsied lung tissue and compared the microscopic findings with radiographic findings on HRCT. They found that there were no apparent lesions of alveolitis in the lung tissues of patients who showed ground-glass opacities on CT scan, instead there were diffusely distributed interstitial granulomas and fibrosis. Therefore, it seems likely that ground-glass opacity reflects the widespread interstitial granulomas of a size below the limits of resolution of CT $(0.5-0.3 \mathrm{~mm})$ with or without perigranulomatous fibrosis. In contrast, thickened bronchovascular bundles observed at CT correspond to granulomatous lesions in the connective tissue sheath around the pulmonary vessels and airways, and a remarkable CT feature may show granulomas in the peribronchovascular connective tissue with fibrosis $[6,15,20]$. Septal lines also represent granulomas in the interlobular interstitium, or occasionally fibrosis around the granulomas $[15,20]$. On the other hand, non septal lines and micro honeycomb or small cystic findings are considered to indicate that the granulomas have been replaced by irreversible fibrotic lesions $[2,7]$. The incidence of non septal lines was lower in the present study $(16 \%)$ than in the study by Remy-Jardin (26\%) [1]. Small cystic changes were seen in only 2 patients. Irregular thickening of bronchial walls or narrowing of the lumen were observed in 16 patients $(64 \%)$, while markedly thickened bronchovascular bundles were seen in only $4(16 \%)$. This means that the number of patients who had advanced sarcoidosis with accompanying fibrotic change was rather small in this study. As previously mentioned, the most frequent findings on HRCT scan in the present study was the dissemination of small nodules of less than $3 \mathrm{~mm}$ diameter, followed by lymphadenopathy in the hilum and mediastinum. These results are compatible with those of previous reports $[4,15,19]$. Small nodules, the confluence of sarcoid granulomas, were most frequent in the peribronchovascular, perilobular and centrilobular interstitium, where there is an abundant lymphatic plexus. This finding strongly supports the importance of the lymph vessels in the pathogenesis of sarcoidosis.

On the other hand, with regard to correlations between visual score based on the HRCT findings, 
and variables of pulmonary function, the visual scores correlated negatively with \%VC, \%FVC, $\% \mathrm{TLC}, \mathrm{FEV}_{1.0} \%$. A statistically negative low correlation was also demonstrated between visual score and \%DLco, but a marked reduction in diffusing capacity was seen in only one patient. This might mean that the severity of the fibrotic changes was milder, however the number of the patients with impairment of diffusion was smaller in the present study than in previous studies. A constrictive ventilatory impairment has been demonstrated in patients with sarcoidosis and has been shown to be due to the diffuse distribution of lesions accompanying the fibrotic changes $[1,3,4,8,15]$. An obstructive ventilatory impairment is not rare in sarcoidosis patients $[1,4,21]$. In the patients of the present study, distortion of the bronchi and bronchiectasis resulting from widespread fibrotic changes was rarely seen, in contrast to the frequent incidence of lesions in the peripheral lung parenchyma. Therefore, the obstructive disturbance is considered to be due to extensive damages in small airways, resulting in reduction in $\mathrm{FEV}_{1.0} \%[9,21] . \mathrm{PaO}_{2}$ was demonstrated to correlate negatively with visual score only when non-smokers were examined. The cause of hypoxemia in nonsmokers with high visual score is not reduction in diffusing capacity but ventilation-perfusion mismatch [9]. There was no distinct correlation between visual score and serum ACE activity, which is similar to the finding in previous reports. ACE is known to be derived from granuloma-forming epithelioid cells and therefore the activity of the enzyme in serum reflects the total amount of granulomas [28]. Okabe et al. [30] however, reported that in-vitro large amounts of lysozyme and ACE are released from epithelioid cell to the medium used for culture but the amount of the latter decreased rapidly and reaches undetectable levels at 3 weeks of culture, while release of lysozyme continues for over one month. Accordingly, epithelioid cells in the mature granulomas which can be recognized on HRCT scan may have stopped or may be about to stop releasing ACE. Silverstein et al. [28] could not demonstrate an elevation of ACE in the sera of sarcoidosis patients with extensive fibrotic changes [28]. The visual score increases in parallel with the progression of the disease because lesions other than granulomas, i.e., fibrotic changes, become prominent on HRCT scan as the disease progresses. Therefore, we considered that there was no positive correlation between visual score and serum ACE.

In many patients in the present study, in whom an apparent ventilatory impairment was not detected by conventional spirometry, the existence of smallairway disease was proven. And in these patients, $\% \dot{\mathrm{V}}_{25}$ and $\dot{\mathrm{V}}_{50} / \dot{\mathrm{V}}_{25}$ were shown to correlate with the value of serum ACE. Also, it is known that in patients with sarcoidosis of stage I, which show only bilateral hilar lymphadenopathy but no parenchymal involvement, impairment of pulmonary function is frequently demonstrated [18,22]. This fact clearly indicates that lesions which are too small to be detected on HRCT scans may possibly impair pulmonary function, depending on the site where the lesions are formed. Miller et al. [16] compared pulmonary function between patients with sarcoidosis of stage I and those of stage II and pointed out that the most frequently encountered impairment in the patients at stage I was small-airway disease. The small-airway disease was considered to be due to stenotic changes of bronchioles caused by the accumulation of granulomas in the peribronchovascular interstitium [9,21,22]. Iwai et al. [10] analyzed the sequential steps of the progress of the disease by histopathological examination of autopsy material from a total of 320 patients with sarcoidosis. They found that sarcoid lesions are most frequently detected in the lung parenchyma and in hilar and mediastinal lymph nodes. In patients having the disease for longer duration, hyalinization of the hilar and mediastinal lymph nodes was common. From the results of the histopathological observation, they suggested that the initial sarcoidosis lesions are formed in the lung and spread to other organs. They also pointed out a possible hematogenous spread, in addition to the lymphogenous dissemination of the disease, based on the finding that granulomas were found not only in the bronchovascular interstitium but also in the alveolar septa which lack lymph ducts, although the latter were less frequent.

It has been shown by Leak and Jamuar [26] that pulmonary lymphatic capillaries begin within the connective tissue area of the terminal and respiratory bronchioles and also within the perivascular connective tissue area around pulmonary arterioles and venulaes, as well as within the pleura and the juxtaalveolar areas of the interlobular septa.

The lymph produced in the peripheral pulmonary connective tissue area passes through lymphatic vessels and drains into hilar and mediastinal lymph nodes and finally into the venous system via the thoracic duct. By assuming that the disease involves the peripheral lung first and then spreads to other organs through the lymphatic system, it will not be 
surprising that small-airway disease is recognized from a very early stage, reflecting the involvement of the interlobular interstitium, and that there is a significant correlation of serum ACE with $\dot{\mathrm{V}}_{25}$ and $\dot{\mathrm{V}}_{50} / \dot{\mathrm{V}}_{25}$ in the early stage of the disease.

\section{CONCLUSION}

The present findings on chest HRCT scans of sarcoidosis patients indicate that the lesions correspond to the distribution of lymphatics in the lung.

This was also proved by the pulmonary function evidence that small-airway disease was recognized at a very early stage of the disease, indicating involvement of the connective tissue sheaths of bronchioles. At an early stage of disease, serum ACE activity was found to be elevated and correlated with $\% \dot{\mathrm{V}}_{25}$ and $\dot{\mathrm{V}}_{50} / \dot{\mathrm{V}}_{25}$, both of which are sensitive indicators of small-airway disease. These findings support the hypothesis that the disease involves first the peripheral connective tissue of the lung and spreads lymphogenously to other sites of the lung and then to other organs.

ACKNOWLEDGMENTS: The author thanks Prof. K. Oizumi of the 1st Department of Medicine, Kurume University and also thanks Prof. N. Hayabuchi and Dr. K. Fujimoto of the Department of Radiology for critical advice and suggestions.

\section{REFERENCES}

1. Remy-Jardin M, Giroud F, Remy J, Wattine L, Wallaert $\mathrm{B}$ et al. Pulmonary sarcoidosis: role of $\mathrm{CT}$ in the evaluation of disease activity and functional impairment and in prognosis assessment. Radiology 1994; 191:675680 .

2. Brauner MW, Lenoir S, Grenier P, Cluzel P, Battesti JP et al. Pulmonary sarcoidosis: CT assessment of lesion reversibility. Radiology 1992; 182:349-354.

3. Muller NL, Mawson JB, Mathieson JR, Abboud R, Ostrow DN et al. Sarcoidosis: correlation of extent of disease at CT with clinical, functional, and radiographic finding. Radiology 1989; 171:613-618.

4. Brauner MW, Grenier P, Mompoint D, Stephane L, Cremoux $\mathrm{H}$ et al. Pulmonary sarcoidosis: evaluation with high-resolution CT. Radiology 1989; 172:467-471.

5. Lenique F, Brauner MW, Grenier P, Battesti JP, Loiseau A et al. CT assessment of bronchi in sarcoidosis: Endoscopic and pathologic correlation. Radiology 1995; 194:419-423.

6. Muller NL, Kullnig P, and Miller RR. The CT findings of pulmonary sarcoidosis: analysis of 25 patients. AJR 1989; 152:1179-1182.

7. Jean M, and Muller NL. Pulmonary sarcoidosis: Change on follow-up CT examination. AJR 1992; 159:473-477.

8. Bergin CJ, Bell DY, Coblentz CL, Chiles C, Gamsu G et al. Sarcoidosis: correlation of pulmonary parenchymal pattern at CT with results of pulmonary function tests. Radiology 1989; 171:619-624.

9. Carrington CB, Gaensler EA, Mikus JP, Schachter AW, Burke GW et al. Structure and function in sarcoidosis. Ann NY Acad Sci 1976; 278:265-283.

10. Iwai K, Takemura T, Kitaichi M, Kawabata $Y$, and Matsui Y. Pathological study on sarcoidosis autopsy. II. early change, mode of progression and death pattern. Acta Pathol Jpn 1993; 43:377-385

11. Iwai K, Tachibana T, Takemura T, Matsui Y, Kitaichi M et al. Pathological studies on sarcoidosis autopsy. I. epidemiological features of 320 cases in Japan. Acta Pathol Jpn 1993; 43:372-376.

12. Takemura T, Matsui $\mathrm{Y}$, Saiki $\mathrm{S}$, and Mikami R. Pulmonary vascular involvement in sarcoidosis: A report of 40 autopsy cases. Hum Pathol 1992; 23:1216-1223.

13. Kitaichi M. Pathology of pulmonary sarcoidosis. Clin Dermatol 1986; 4:108-115.

14. Lacronique J, Bernaudin JF, Soler $\mathrm{P}$, Lange $\mathrm{F}$, Kawanami $\mathrm{O}$ et al. Alveolitis and granulomas: Sequential course in pulmonary sarcoidosis. In: Sarcoidosis, ed. Chretien J, Marsac J and Saltiel JC, Pergamon Press, Paris, pp36-41, 1983.

15. Webb WR, Muller NL, and Naidich DP. High Resolution CT, 2nd edition, Lippincoott-Raven, Pennsylvania, pp158-166, 1996

16. Miller A, Chuang M, Teirstein AS et al. Pulmonary function in Stage I and II pulmonary sarcoidosis. Ann NY Acad Sci 1976; 278:292-300.

17. Grenier P, Valeyre D, Cluzel P, Brauner MW, Lenoir S et al. Chronic diffuse interstitial lung disease: Diagnostic value of chest radiography and high-resolution CT. Radiology 1991; 179:123-132.

18. Sharma OP, Colp C, and Williams MH. Pulmonary function studies in Sarcoidosis in patients with bilateral sarcoidosis of hilar lymph nodes. Arch Intern Med 1966; 117:436-439.

19. Gruden FJ, Webb WR, and Wornock M. Centrilobular opacities in the lung on high-resolution CT: Diagnostic considerations and pathologic correlation. AJR 1994; 162:569-574.

20. Nishimura K, Itoh H, Kitaichi M, Nagai S, and Izumi T. Pulmonary sarcoidosis: Correlation of CT and histopathologic findings. Radiology 1993; 189:105-109.

21. Levinson RS, Metzger LF, Stanley NN, Kelsen SG, Altose MD et al. Airway function in sarcoidosis. Am $\mathbf{J}$ Med 1977; 63:51-59.

22. Gleeson FV, Traill ZC, and Hansell DM. Evidence on expiratory CT scan of small-airway obstruction in sarcoidosis. AJR 1996; 166:1052-1054.

23. Stern EJ, and Frank MS. Small-airway disease of the lungs: Findings at expiratory CT. AJR 1994; 163:37-41.

24. Hartman TE, Primack SL, Lee KS, Swensen SJ, and Muller NL. CT of bronchial and bronchiolar diseases. Radiographics 1994; 14:991-1003

25. Takishima T, Sakaki T, Takahashi K, Sakai H, and Nakamura T. Direct-writing recorder of the flow-volume curve and its clinical application. Chest 1972; 61:262-266.

26. Leak LV, and Jamuar MP. Ultrastructure of pulmonary 
lymphatic vessels. Am Rev Respir Dis 1983; 128:S58S65.

27. Lauweryns JM. The juxta-alveolar lymphatics in the human adult lung. Am Rev Respir Dis 1970; 102:877885.

28. Silverstein E, Friedland J, Lyons HA, and Gourin A. Elevation of angiotensin-converting enzyme in granulomatous lymph nodes and serum in sarcoidosis: Clinical and possible pathogenic significance. Ann NY Acad Sci 1976; 278:498-513.

29. Lieberman J, Nosal A, Schlessner LA, and Foken AS. Serum angiotensin-converting enzyme for diagnosis and therapeutic evaluation of sarcoidosis. Am Rev Respir Dis $1979 ; 120: 329-335$.

30. Okabe T, Suzuki A, Ishikawa H, Yotsumoto H, and Ohsawa N. Cell originating from sarcoid granulomas in vitro. Am Rev Respir Dis 1981; 124:608-612.
31. Lieberman J. Elevation of serum angiotensin-converting enzyme level in sarcoidosis. Am J Med 1975; 59:385364.

32. Takemura T, Matsui $\mathrm{Y}$, Oritsu M, Akiyama O, Hiraga $\mathrm{Y}$ et al. Pulmonary vascular involvement in sarcoidosis: granulomatous angiitis and microangiography in transbronchial lung biopsies. Virchow Arch A Pathol Anat 1991; 418:361-368

33. Ichikawa Y, Fujimoto K, Shiraishi T, and Oizumi K. Primary cavitary sarcoidosis: High-Resolution CT findings. AJR 1994; 163:745.

34. Rohatgi PK, and Schwab LE. Primary acute pulmonary cavitation in sarcoidosis. AJR 1980; 134:1199-1203.

35. Murata K, Khan A, and Herman PG. Pulmonary parenchymal disease: Evaluation with high-resolution CT. Radiology 1989; 170:629-635. 